\title{
VOXEL-WISE ANALYSES OF THE IMPACT OF HIGH- FAT DIET ON BRAIN STRUCTURE IN WISTAR RATS
}

\author{
Piotr MAJKA' ${ }^{1}$, Zuzanna SETKOWICZ², Stefan P. GAŹDZIŃSKI ${ }^{3}$ \\ 1 Nencki Institute for Experimental Biology, Polish Academy of Sciences, Warsaw, Poland \\ 2 Department of Neuroanatomy, Jagiellonian University, Krakow, Poland \\ 3 Creative Neuroscience Lab - CNS Lab, Military Institute of Aviation Medicine, Warsaw, Poland
}

Source of support: Polish National Science Centre, grant no: 2011/03/B/NZ4/03771.

Author's address: Stefan P. Gaździński, Military Institute of Aviation Medicine, Krasińskiego 54/56 Street, 01-755 Warsaw, Poland, e-mail: stefan.gazdzinski@yahoo.com

Abstract: Recent studies at our institution have demonstrated an obesity problem among Helicopter Emergency Medical Service Pilots, similar to obesity problems encountered in other militaries. As obesity is associated with poorer cognitive performance, it may endanger mission objectives and safety of the crew. Maintaining lean body mass is important, but the effects of various nutrients on the brain and its performance have to be investigated in animal studies. Here, we discuss the methodological issues related to evaluation of this matter in animal (rat) models. Using ROI analyses, we have recently observed that a one-year application of high fat diet (HFD) that induced mild ketonemia lead to better learning and memory, larger hippocampi volumes, as well as spectroscopic changes consistent with these results in Wistar rats compared to regular chow (CON; Setkowicz et al., 2015). Here, we applied voxel-wise analysis to determine focal changes in brain tissue structure. Furthermore, we compared the effects of template selection (Valdés-Hernández et. al. template vs. study specific template) on the results.

Twenty five male Wistar rats were put on HFD (60\% calories from fat, $28 \%$ from sugars and $7 \%$ from proteins) on their 55 th day of life, while 25 CON remained on regular chow. Structural T2-weighted TurboRARE images were acquired at 7T. Eighteen datasets acquired for CON, 18 datasets for HFD were selected for analyses. Image of each specimen was registered into the Valdés-Hernández et. al. template or study-specific template created based on all the data.

Figures: 4 • References: 23 • Full-text PDF: http://www.pjambp.com • Copyright (C 2018 Polish Aviation Medicine Society, ul. Krasińskiego 54/56, 01-755 Warsaw, license WIML •Indexation: Index Copernicus, Polish Ministry of Science and Higher Education 
Majka P. et al. - Voxel-wise analyses ...

Hippocampal volumes were larger in rats on the HFD than in controls, especially in the hippocampal CA1 field, but also in the surrounding cortical areas including entorhinal and temporal association cortex, regardless of the template used. Analysis with a study specific template does not show regions of smaller volumes in the HFD group compared to the CON.

The results confirm our ROI findings of larger hippocampal volumes in rats on the HFD, but also point to focal volume increases. Our results do not support the thesis that HFD per se does not necessarily lead to degeneration of the nervous system. They also point to the need of using a study specific template, as it is common in human studies.

Keywords: magnetic resonance imaging, voxel-based morphology, template, high-fat diet, in-vivo, hippocampus, long-term effect

\section{INTRODUCTION}

Recent studies at our institution have demonstrated an obesity problem among Helicopter Emergency Medical Service Pilots [8], firefighters [12], similar to obesity problems encountered in the military $[14,17,22]$. As obesity is associated with poorer cognitive performance (reviewed in [11], it may endanger mission objectives and safety of the (rew), maintaining lean body mass is important, but the effects of various nutrients on the brain and its performance have to be investigated in animal studies. Here, we discuss the methodological issues related to the evaluation of this matter in animal (rat) models. In our study, evaluating the effects of one-year high fat diet (HFD), leading to mild ketonemia, on hippocampal size in Wistar rats we unexpectedly observed larger hippocampal volumes compared to the control group fed with chow [16]. These changes were accompanied by better learning and memory skills throughout the experiment, as measured at an 8-arm maze, as well as higher concentrations of total NAA (tNAA: $\mathrm{N}$-acetylaspartate and $\mathrm{N}$-acetylaspartateglutame; marker of neuronal viability), total Cho (tCho: Glycerophosphocholine + Phosphocholine, which are believed to be primarily involved in cell membrane breakdown and synthesis) and total $\mathrm{Cr}(\mathrm{tCr}$ : creatine + phospo-creatine - involved in cell bioenergetics).

In our volumetric analyses, we utilized a template that was developed for rats between sixth and tenth week [20], whereas our animals were about 50 weeks old at the time of study. Furthermore, in our previous manuscript [16] we noted some similarities of our results to human studies on individuals on high fat diets.

Here, we applied voxel-wise analysis to determine focal changes in brain tissue. Furthermore, we compared the effects of template selection (Valdés-Hernández et. al. template [20] vs. study specific template) on the results. Finally, we measured concentrations of total cholesterol, $\mathrm{HDH}$ cholesterol, triglycerides, and blood glucose to evaluate whether our diet lead to similar changes as low carbohydrate diets in humans that also provide $60 \%$ energy from fat (e.g., $[3-5,9])$.

\section{MATERIALS AND METHODS}

\section{Animals}

The methods were described in detail in [16]. In short, male Wistar rats aged 45-50 days were randomly divided into two groups, i.e. the rats on the HFD and the controls (CONs) fed a standard control diet (Labofeed-Morawski, Poland). The HFD provided $61 \%$ energy from fats, $28 \%$ from sugars, and $11 \%$ from proteins. The control diet provided $14 \%$ energy from fats, $51 \%$ from carbohydrates, and $35 \%$ from proteins. The groups had similar caloric intake and the rats on the HFD had similar body mass as the CONs, consistent with previous studies that did not observe differences in body mass between obese and control groups (e.g., $[1,13,15])$. However, at the time of being sacrificed, the rats on the HFD had 38\% more epididymis fat, an accepted marker of fatness in rats [10], consistent with the planned effects of the diet. Blood level of sugar in the rats on the HFD was significantly elevated after the 8th month of the experiment, but still within normal values. Blood concentrations of ketone bodies were elevated throughout the experiment in the rats on the HFS compared to the CONs, reaching the range of mild ketonemia [6]. At the time of being sacrificed, the rats on the HFD had $5.8 \%$ heavier brains than the CONs. 
The details can be found in [16]. All animals underwent a structural MRI study at their 12th month of life. All procedures involving the use of animals were approved by the Bioethical Commission of the Jagiellonian University in Krakow, Poland, in accordance with international standards.

\section{Magnetic Resonance image acquisition and processing}

At one month and at 12 months, brains of the examined animals were scanned with the Bruker BioSpec 70/30 Avance III system working at 7T, with a transmit cylindrical radiofrequency coil (15 $\mathrm{cm}$ inner diameter) and a receive-only coil array ( $2 \times 2$ elements) positioned over the animal's head. The animals were positioned prone with the head placed in the stereotactic apparatus and were anesthetized with a $1.5 \%$ isoflurane in a mixture of oxygen and air. Respiration, heart rate, and oxygen saturation were monitored throughout the experiment. Rectal temperature was kept at $370 \mathrm{C}$ by placing the animal on top of a temperature controlled warm water blanket. Tripilot scans were used for accurate positioning of the animals inside the magnet.

Structural MR images covering the brain without the olfactory bulb were acquired with T2weighted TurboRARE (TR/TE $=4700 / 30 \mathrm{~ms}$, RARE factor $=4$, resolution $=125 \times 125 \times 500 \mu \mathrm{m}$, no gap, $\mathrm{NEX}=7, \mathrm{TA}=27 \mathrm{~min}$ ) for brain parcellation (see below).

MR images were resampled to an isotropic resolution of $125 \mu \mathrm{m} / \mathrm{vox}$ and then processed with the N4 algorithm [19] to correct for intensity inhomogeneity. Afterwards, a single image was chosen randomly and the brain outline was drawn semi automatically using the ITK-Snap software [23] and transferred to the other images using the Symmetric normalization (SyN) nonlinear image registration algorithm (the ANTS software package [2]). Skull stripped brain images were then parceled by warping to the template proposed by Valdes-Hernandez et al. [20] that included 50 brain, mostly cortical regions. This template was extended by manual parcellation of the hippocampus. All parceled images were visually reviewed to assure quality. Exemplary parcellation of the hippocampi is depicted in fig. 4. Absolute volumes were reported. Additionally, to account for intersubject variability, hippocampal volumes were scaled to the whole brain and compared between groups.

Eighteen datasets acquired for the CONs and 18 datasets for the rats on the HFD were selected for analyses. To be included, they needed to contain the entire brain with olfactory bulb and cerebellum, as well as pass our stringent quality control criteria. Images resampled to isotropic resolution of $125 \mu \mathrm{m} /$ vox and processed with N4 algorithm to correct for intensity inhomogeneity. Image of each specimen was registered into the Valdés-Hernández et. al. [20], template or the study-specific template using the SyN algorithm [2] resulting in a series of deformation fields. A Jacobian determinant of each deformation field was then computed and modulated with a gray

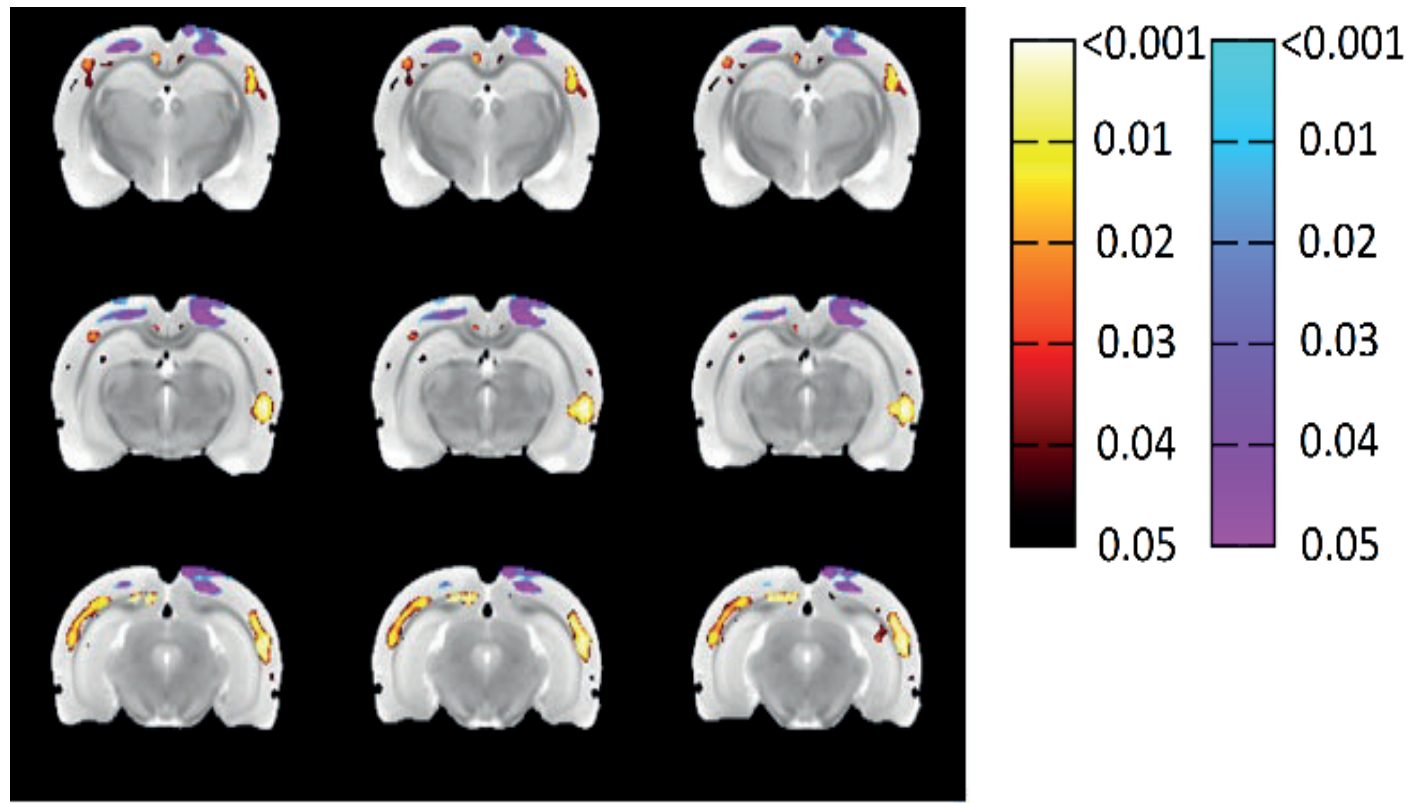

Fig. 1. Regions of larger volume in rats on the HFD than in CONs; Valdés-Hernández template was used (selected slices). Please note focal contractions. P-values maps of local, voxel-wise volume expansions (black-red-yellow-white) and contractions (magenta-blue). 


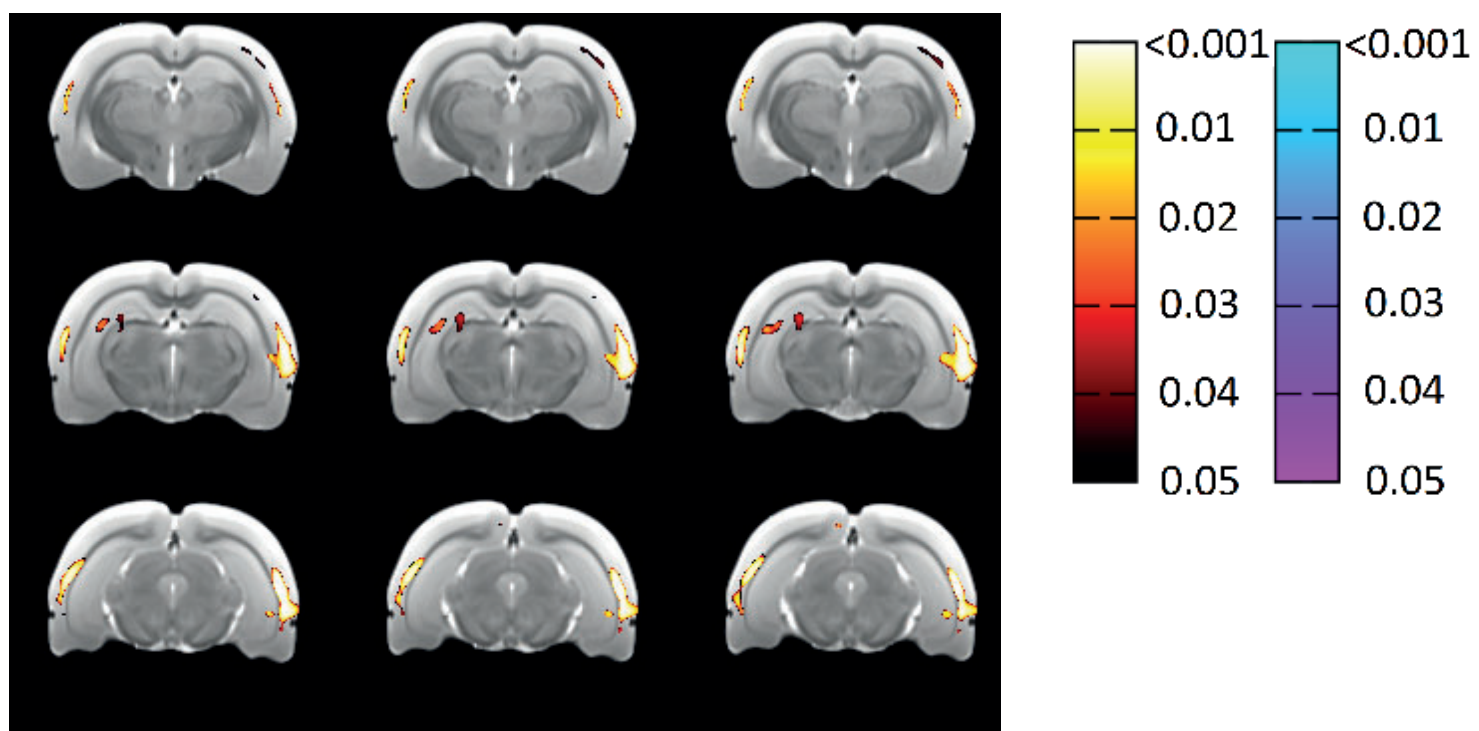

Fig. 2. Regions of larger volume in rats on the HFD than in CONs (selected slices); study specific template was used. No volume contractions visible. P-values maps of local, voxel-wise volumes expansions (black-red-yellow-white) and contractions (magenta-blue).

matter probability, blurred with a Gaussian filter of $250 \mu \mathrm{m}$. In the second approach, a study specific template [2] based on all 36 specimen was generated. Further procedures were analogous to those described in [20].

\section{Statistical analyses}

Significance of the differences between the CONs and the rats on the HFD was determined with a two-sample unpaired t-test. The ThresholdFree Cluster Enhancement permutation method [3] was used to threshold t-maps (FSL-randomize software). The tests utilized 10,000 permutations and $p=0.05$ was chosen as a significance threshold.

\section{RESULTS}

Hippocampal volumes are larger in rats on the HFD than in controls, especially in the hippocampal CA1 field, but also in the surrounding cortical areas, regardless of the template used (see fig. 1 and fig. 2). Analysis with a study-specific template does not show regions of smaller volumes in the rats on the HFD, as compared to the CONs (compare fig. 1 and fig. 2).

\section{Discussion}

All cross-sections for the Valdés-Hernández template and for the study specific template, respectively, are depicted in fig. 3 and fig. 4 .

We observed volumetric increases in the hippocampi and point to focal volume increases in the temporal association cortex, the entorhinal cortex, and others using the study specific tem- plate. Interestingly, when using literature-based atlas [20], we also observed tissue contractions that were not observed with the study specific template.

The results confirm our ROI findings of larger hippocampal volumes in rats on the HFD [16]. Moreover, the use of the study specific template yielded similar regions of tissue expansion due to the HFD, but regions of tissue contraction were absent.

Rats on the HFD exhibited higher blood glucose (measured in the evening, so reflecting fasting blood glucose) than the controls, but within normal range. Lower total cholesterol and a trend for lower triglycerides are not commonly associated with high fat diets. However, high fat diets with low carbohydrate content do not necessarily lead to elevated cholesterol and triglyceride content $[7,9]$. Interestingly, low carbohydrate diets that generally provide about $60 \%$ of calories from fat were proven to lead to weight loss and remission of diabetes (e.g., [18]), although in real life, due to poor compliance, the caloric intake from carbohydrates reaches even $45 \%$ (reviewed in [21]). Such low carbohydrate diets are designed to induce ketonemia.

\section{CONCLUSION}

The results confirm our ROI findings of larger hippocampal volumes in rats on the HFD, but also point to focal volume increases in the temporal association cortex and the entorhinal cortex. Our results do not support the thesis that the HFD per se leads to degeneration of the nervous system. 


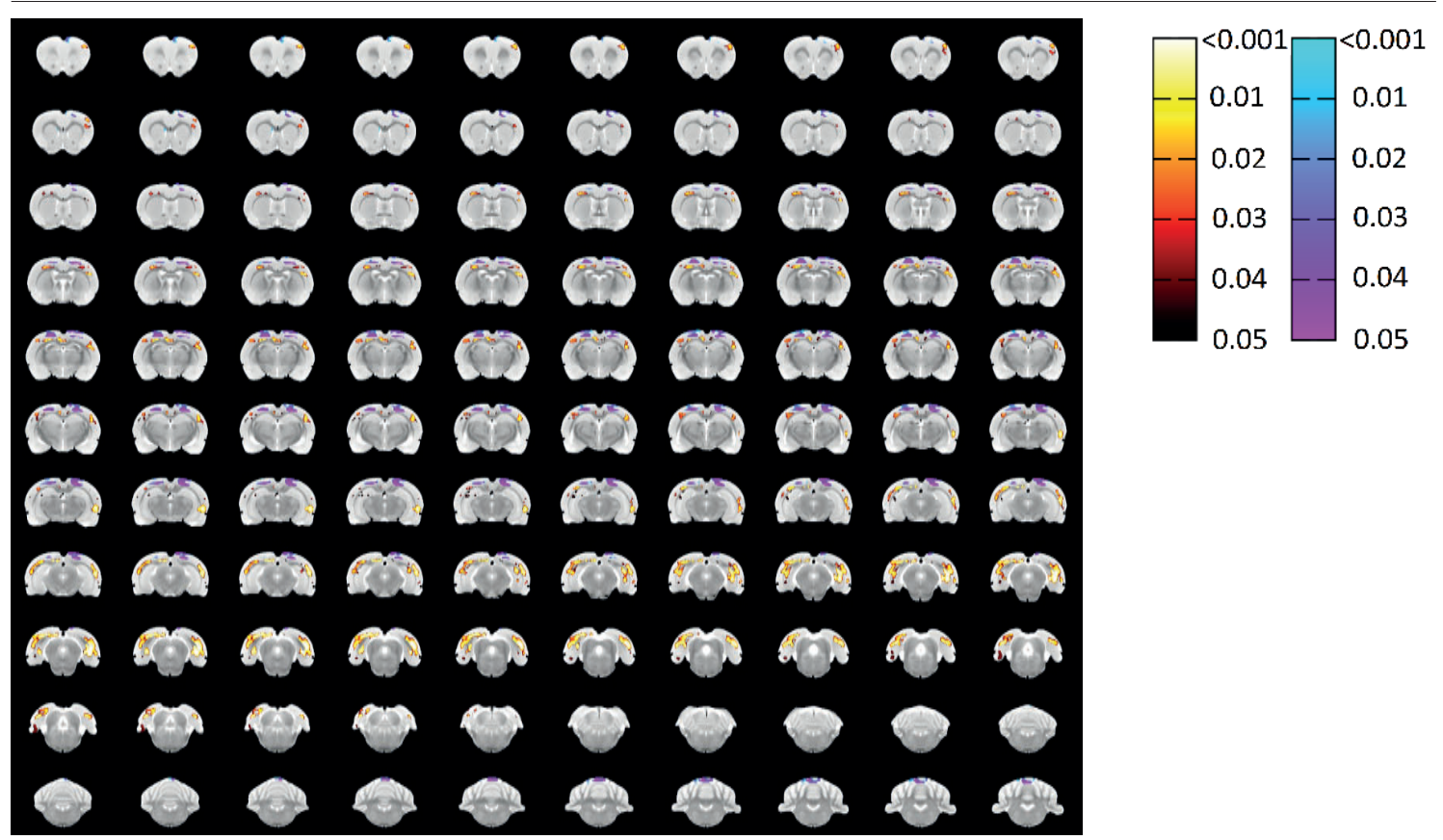

Fig. 3. Regions of larger volume in rats on the HFD than in CONs (all cross-sections); Valdés-Hernández template was used. Please note focal contractions. P-values maps of local, voxel-wise volumes expansions (black-red-yellowwhite) and contractions (magenta-blue).

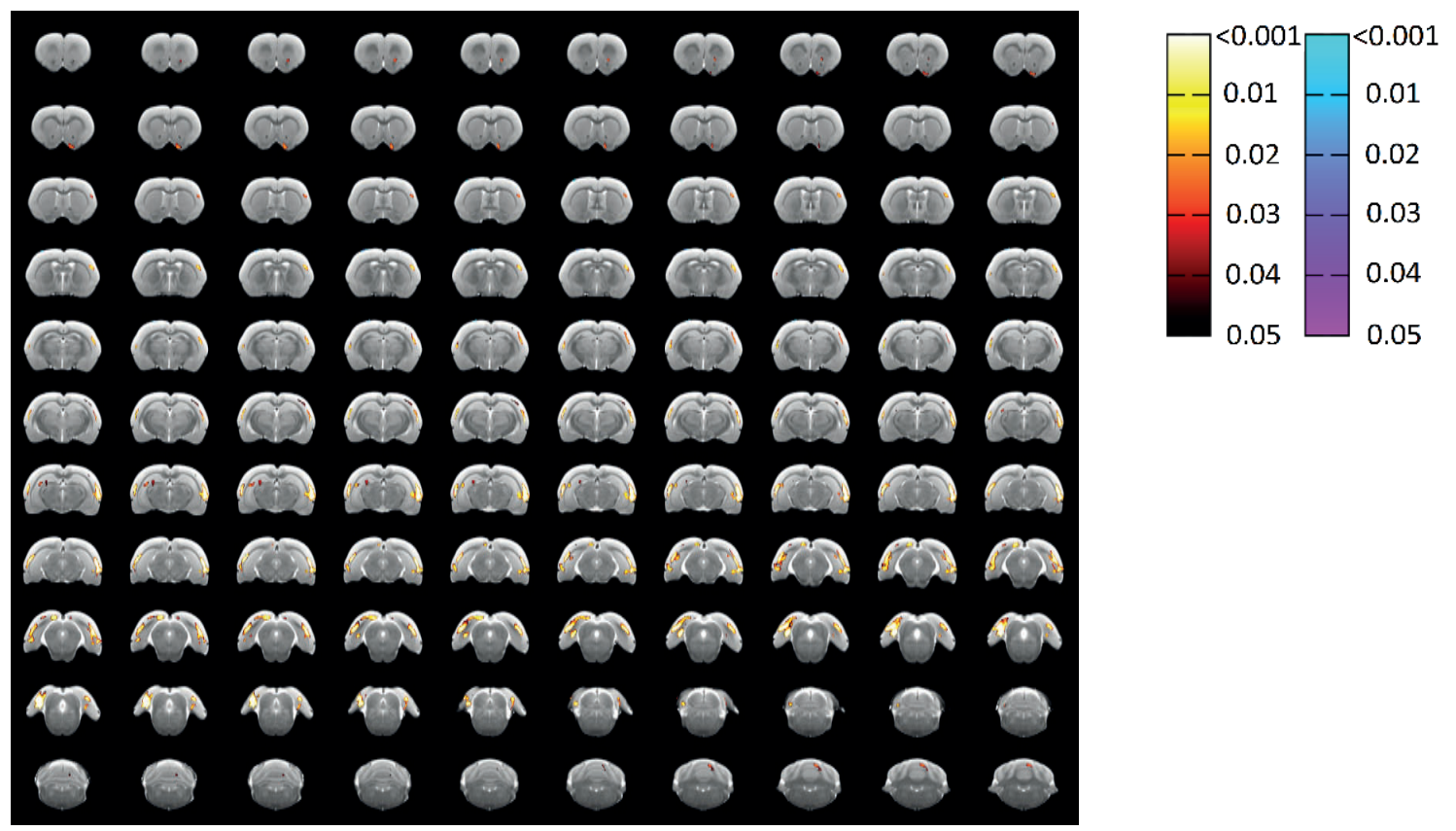

Fig. 4. Regions of larger volume in rats on the HFD than in CONs (all cross-sections); study specific template was used. No volume contractions visible. P-values maps of local, voxel-wise volumes expansions (black-red-yellow-white) and contractions (magenta-blue).

Furthermore, our results support the use of studyspecific templates in animal studies. Taken togeth- er, the animal models may be used to evaluate the effects of selected nutrients on the brain.

\section{ACKNOWLEDGEMENTS}

We extend our gratitude to Jarosław Orzeł and Bartosz Kossowski for providing volumetric data in the appropriate format. 


\section{AUTHORS' DECLARATION:}

Study Design: Piotr Majka, Zuzanna Setkowicz, Stefan P. Gaździński. Data Collection: Piotr Majka, Stefan P. Gaździński. Manuscript preparation: Piotr Majka, Zuzanna Setkowicz, Stefan P. Gaździński. Funds Collection: Stefan P. Gaździński. The Authors declare that there is no conflict of interest.

\section{REFERENCES}

1. Auer MK, Sack M, Lenz JN, Jakovcevski M, Biedermann SV, Falfan-Melgoza C, et al. Effects of a high-caloric diet and physical exercise on brain metabolite levels: a combined proton MRS and histologic study. Journal of Cerebral Blood Flow and Metabolism. 2015; 35(4):554-564.

2. Avants BB, Epstein CL, Grossman M, Gee JC. Symmetric diffeomorphic image registration with cross-correlation: Evaluating automated labeling of elderly and neurodegenerative brain. Medical Image Analysis. 2008; 12(1):26-41.

3. Brinkworth GD, Buckley J, Noakes M, Clifton P, Wilson C. Long-Term Effects of Very Low and High Carbohydrate Weight Loss Diets on Mood and Cognitive Performance. Obesity. 2009; 17:S77

4. Brinkworth GD, Buckley JD, Noakes M, Clifton PM, Wilson CJ. Long-term Effects of a Very Low-Carbohydrate Diet and a Low-Fat Diet on Mood and Cognitive Function. Archives of Internal Medicine. 2009; 169(20):1873-1880.

5. Brinkworth GD, Noakes M, Clifton PM, Buckley JD. Effects of a Low Carbohydrate Weight Loss Diet on Exercise Capacity and Tolerance in Obese Subjects. Obesity. 2009; 17(10):1916-1923.

6. Courchesne-Loyer A, Fortier M, Tremblay-Mercier J, Chouinard-Watkins R, Roy M, Nugent S, et al. Stimulation of mild, sustained ketonemia by medium-chain triacylglycerols in healthy humans: Estimated potential contribution to brain energy metabolism. Nutrition. 2013; 29(4):635-640.

7. Dyerberg J, Bang HO, Hjorne N. PLASMA CHOLESTEROL CONCENTRATION IN CAUCASIAN DANES AND GREENLAND WEST-COAST ESKIMOS. Danish Medical Bulletin. 1977; 24(2):52-55.

8. Galazkowski R, Gazdzinska A, Kopka M, Drozdowski R, Wylezol M. Evaluation of overweight and obesity in Helicopter Emergency Medical Service (HEMS) worker. Annals of Agricultural and Environmental Medicine. 2015; 22(3):542-545.

9. Grieb P, Klapcinska B, Smol E, Pilis T, Pilis W, Sadowska-Krepa E, et al. Long-term consumption of a carbohydrate-restricted diet does not induce deleterious metabolic effects. Nutrition research (New York, NY). 2008; 28(12):825-833.

10. Iritani N, Fukuda H, Tada K. Nutritional regulation of lipogenic enzyme gene expression in rat epididymal adipose tissue. Journal of Biochemistry. 1996; 120(2):242-248.

11. Janewicz M, Binder M, Gaździńska A, Truszczyński OE, Mojkowska A, Zieliński P, et al. Cognitive improvements following body mass reduction induced by intragastric balloon in morbidly obese patients. A preliminary study. The Polish Journal of Aviation Medicine, Bioengineering and Psychology. 2018; 24(3):5-12.

12. Kaipust CM, Jahnke SA, Poston WSC, Jitnarin N, Haddock CK, Delclos GL, et al. Sleep, Obesity, and Injury Among US Male Career Firefighters. J Occup Environ Med. 2019; 61(4):E150-E154.

13. Kloeckener T, Hess S, Belgardt BF, Paeger L, Verhagen LaW, Husch A, et al. High-fat feeding promotes obesity via insulin receptor/PI3K-dependent inhibition of SF-1 VMH neurons. Nature Neuroscience. 2011; 14(7):911-U139.

14. Kłosowski M, Dębska A, Stelęgowski A. Ocena problemu nadwagi u podchorążych i pilotów wojskowych w wieku 18-45 lat. Nowiny Lekarskie. 2008; 3:31-42.

15. Koenner AC, Janoschek R, Plum L, Jordan SD, Rother E, Ma X, et al. Insulin action in AgRP-expressing neurons is required for suppression of hepatic glucose production. Cell Metabolism. 2007; 5(6):438-449.

16. Setkowicz Z, Gazdzinska A, Osoba JJ, Karwowska K, Majka P, Orzel J, et al. Does Long-Term High Fat Diet Always Lead to Smaller Hippocampi Volumes, Metabolite Concentrations, and Worse Learning and Memory? A Magnetic Resonance and Behavioral Study in Wistar Rats. Plos One. 2015; 10(10).

17. Shams-White M, Deuster P. Obesity Prevention in the Military. Current Obesity Reports. 2017; 6(2):155-162.

18. Tay J, Luscombe-Marsh ND, Thompson CH, Noakes M, Buckley JD, Wittert GA, et al. Comparison of low-and high-carbohydrate diets for type 2 diabetes management: a randomized trial. American Journal of Clinical Nutrition. 2015; 102(4):780-790.

19. Tustison NJ, Avants BB, Cook PA, Zheng Y, Egan A, Yushkevich PA, et al. N4ITK: Improved N3 Bias Correction. IEEE Transactions on Medical Imaging. 2010; 29(6):1310-1320. 
20. Valdes-Hernandez PA, Sumiyoshi A, Nonaka H, Haga R, Aubert-Vasquez E, Ogawa T, et al. An in vivo MRI Template Set for Morphometry, Tissue Segmentation, and fMRI Localization in Rats. Frontiers in neuroinformatics. 2011; 5:26.

21. Van Wyk HJ, Davies JS, Davis RE. A critical review of meta-analyses of low carbohydrate diets in subjects with Type 2 diabetes. Diabetic Medicine. 2015; 32:52.

22. Webber BJ, Ruiz SA, Talcott GW, Little MA, Tate DF. Weight Gain of Service Members After Basic Military Training. American Journal of Preventive Medicine. 2020; 58(1):117-121.

23. Yushkevich PA, Piven J, Hazlett HC, Smith RG, Ho S, Gee JC, et al. User-guided 3D active contour segmentation of anatomical structures: Significantly improved efficiency and reliability. Neuroimage. 2006; 31(3):1116-1128.

Cite this article as: Majka P, Setkowicz Z, Gaździński SP. Voxel-Wise Analyses Of The Impact Of High-Fat Diet On Brain Structure In Wistar Rats. Pol J Aviat Med Bioeng Psychol 2018; 24(4): 20-26. DOI: 10.13174/pjambp.25.05.2020.02 